\title{
Seizure Control After Stimulation of the Vagus Nerve: Clinical Outcome Measures
}

\author{
Beverley M. Clarke, A.R.M. Upton, Helene Griffin, Debbie Fitzpatrick and \\ Marijane DeNardis
}

\begin{abstract}
Background: Currently, decreases in seizure frequency are the accepted efficacy outcome measure of therapeutic interventions in the management of patients with epilepsy. In a longitudinal randomized controlled trial of 10 subjects with intractable complex partial seizures who received left vagal nerve stimulation (VNS) to control seizures, it was found that the total number of consecutive seizure-free days is a significant efficacy outcome measure. Unlike measures in which percentage decreases in seizure frequency are calculated, measures of consecutive seizure days indicate improvement in the amount of time for which patients may function at a higher level in activities of daily living. Methods: Fourteen day blocks of consecutive seizure-free days and 14 day blocks of consecutive days in which subjects had seizures were tabulated. Results: A Pearson correlation coefficient showed that prior to VNS subjects had few, if any, seizure free blocks of time and after VNS they had more blocks of time seizure free $r=-1.00$ and $r=-0.99$. The blocks of seizure-free days increased tenfold ( $\mathrm{x} 0.85$ to $\overline{\mathrm{x}} 8.00$ ) from 1991-1995 while mean seizure frequency in those blocks in which subjects had seizures only decreased from $(\bar{x} 20.14$ to $\bar{x} 17.59)$ for the same time period. Correlations between total number of seizures after 24 months of VNS and after 50 months of VNS were $r=0.85$ showing a consistency in the effect of VNS. Conclusions: Monitoring the number of consecutive seizure-free days is a significant clinical outcome measure of VNS.
\end{abstract}

\begin{abstract}
RÉSUMÉ: Contrôle des crises d'épilepsie après stimulation du nerf vague: mesure des résultats cliniques. Introduction: Présentement, la diminution de la fréquence des crises est la mesure acceptée de l'efficacité de l'intervention thérapeutique dans le suivi des patients atteints d'épilepsie. Dans une étude longitudinale randomisée, contrôlée par placebo, de 10 sujets présentant des crises complexes partielles résistantes au traitement, qui ont été traités par stimulation du nerf vague gauche (SNV) pour contrôler les crises, on a constaté que le nombre de jours consécutifs sans crise est une mesure significative de l'efficacité thérapeutique. Contrairement aux mesures obtenues en calculant le pourcentage de diminution de la fréquence des crises, la mesure des jours consécutifs sans crise indique l'amélioration dans la quantité de temps pendant laquelle les patients peuvent fonctionner à un niveau plus élevé dans les activités de la vie quotidienne. Méthodes: Des blocs de quatorze jours consécutifs sans crise et de quatroze jours consécutifs où les sujets ont eu des crises ont été relevés. Résultats: Le coefficient de corrélation de Pearson a montré qu'avant la SNV, les sujets avaient peu ou pas de blocs de jours sans crise et après la SNV, ils avaient plus de blocs de jours sans crise $\mathrm{r}=-1.00$ et $\mathrm{r}=-0.99$. Les blocs de jours sans crise ont augmenté de dix fois $(\overline{\mathrm{x}} 0.85$ à $\overline{\mathrm{x}} 8.00)$ de 1991 à 1995 alors que la fréquence moyenne des crises dans les blocs où les sujets avaient des crises a diminué seulement de $(\bar{x} 20.14$ à $\bar{x} 17.59)$ pendant la même période. Les corrélations entre le nombre total des crises après 24 mois de SNV et après 50 mois de SNV étaient $r=0.85$ démontrant une constance dans l'effet de la SNV. Conclusion: La surveillance du nombre de jours consécutifs sans crise est une mesure significative des résultats cliniques de la SNV.
\end{abstract}

Can. J. Neurol. Sci. 1997; 24: 222-225

Stimulation of the vagus nerve (VNS) in animals has shown that VNS can produce synchronization or desynchronization of the electroencephalogram (EEG) depending on the stimulus parameters used. ${ }^{(1-11)}$ Early studies of left vagal nerve stimulation $^{(12-14)}$ in man have shown that seizures can be aborted in some cases and significantly decreased (50\%) in others after 24 months of VNS. These studies show that cessation of seizures does not suddenly occur after implantation of a VNS pacemaker.
Assessment of data collected by the Vagus Nerve Stimulation Study Group ${ }^{(15)}$ shows that $75 \%$ of all studies continue treatment for greater than 24 months. Currently, decisions to continue

\footnotetext{
From the Division of Neurology, McMaster University Medical Centre, Hamilton. RECEIVED JULY 29, 1996. ACCEPTED IN FINAL FORM FEBRUARY 4, 1997.

Reprint requests to: Beverley M. Clarke, Division of Neurology - 4U6, McMaster University Medical Centre, 1200 Main Street W., Hamilton, Ontario, Canada L8N 3Z5
} 
VNS at any point in time are reported to be based on patient and physician determinations of benefit. This benefit is usually based on whether there is a decrease or cessation in total number of seizures. Our long term follow up studies of ten (10) epileptic subjects, in which there was no significant change in anticonvulsant drug levels, after chronic stimulation (50 months) of the vagal nerve to control seizures, show that such decisions should be determined by calculating not only the total number of seizures but also collation of the total number of consecutive seizure-free days. The cost-effective, evidence based management of patients with epilepsy receiving VNS will be greatly enhanced by including the collation of consecutive seizure-free days and will ensure that VNS is not inappropriately discontinued or prolonged in intractable cases. This work was done at McMaster University Medical Centre, Hamilton, Ontario, Canada and is part of the Vagus Nerve Study Group, Cyberonics Inc. The project was approved by the Medical Ethics Committee of McMaster University Medical Centre and was supported by the Michael DeGroote Foundation for epilepsy research.

\section{METHODS}

Of ten subjects, eight subjects, (6 males, 2 females) with intractable complex partial seizures were implanted with a Neurocyberonics pacemaker Model 100, Cyberonics Inc. Webster, Texas, U.S.A. Two male subjects received a Medtronics device Model 7420, Medtronic Canada, Mississauga, Ontario, Canada. The mean age of the subjects was $34 \pm 8.23$ S.D. years, and all had had intractable complex seizures for more than 20 years (there was no significant improvement in total number of seizures reported over the past 10 years and subjects were not suitable candidates for surgery). Inclusion criteria were that subjects must have had at least 6 seizures/month with no more than 14 days between seizures. The 2 subjects on the Medtronic device were on 4 anticonvulsant medications while 8 subjects were on 3 anticonvulsant drugs. Dosages were kept constant and remained at therapeutic levels throughout the study. Exclusion criteria were that subjects had no evidence of any other neurological disorder or pregnancy. Baseline seizure diary records were kept pre-operatively by 8 subjects and their families for a period of 4-6 months while 2 subjects had less than 1 month pre-operative records. Seizure data were then collected continuously post operatively. Data analyses using analysis of covariance techniques were done on the 8 complete data sets. The study was a randomized design in which both examiner and subject were blinded to stimulation frequency. Initially there were two groups, a low frequency group with stimulation parameters of 0.25-3.00 $\mathrm{mA}$ (range), 1 $\mathrm{Hz}, 130 \mu \mathrm{sec}$ pulse width and a high frequency group with parameters of $0.25-3.50 \mathrm{~mA}$ (range), $30 \mathrm{~Hz}, 500 \mu \mathrm{sec}$ pulse width. Low level stimulation produced an $8 \%$ decrease in total number of seizures, whereas high levels produced a $50 \%$ effect. There is a dose response effect. After 12 weeks, all subjects received high frequency stimulation. Data analysis involved collating the number of 14 day blocks in which subjects had seizures in a given calendar year and the number of blocks (14 consecutive days) in which subjects were seizure-free. There are a total of 26 blocks in a given year. A Pearson correlation coefficient was used to determine the relationship between the 2 groups.
Analysis of covariance was used to determine whether there was a significant difference in the mean number of seizure-free blocks over time and whether there was a significant difference in the mean number of seizures in those blocks in which subjects had seizures. The correlation between total number of seizures pre-operatively and post stimulation and the effect of VNS on total number of seizures after 28 months of stimulation and then after 50 months was also done to determine whether there was a significant difference in seizure frequency pre-operatively and after stimulation. Percentage decreases in total number of seizures were available for 9 of the 10 subjects because 1 subject died from causes unrelated to VNS.

\section{REsults}

While it may be anticipated by subjects that their seizures will suddenly stop immediately after surgery, raw data analysis showed that the total number of seizures seems to alternately decrease and increase in erratic patterns before cessation occurs. However, the blocks of consecutive seizure days show more consistent increases over time (See examples, Figures 1-6). Individual results from 9 subjects shows total percentage decreases (pre-implant compared with values after 50 months VNS) of $89 \%, 85 \%, 84 \%, 64 \%, 43 \%, 35 \%$, and $12 \%$ respectively. In one subject there was a $14 \%$ increase in total number of seizures and one subject has been seizure-free for $361 / 2$ months and continues. Results from data analysis in which time was divided into 14 day blocks of consecutive seizure-free days and 14 day blocks in which there were seizures, showed that the Pearson Correlation coefficient between the groups pre-operatively, was $r=-21$ because prior to VNS, subjects had few, if any, 14 day blocks of seizure-free days. After VNS, correlations were very strong $r=-1.00$ and $r=-.99$ between the 2 groups indicating that blocks of seizure-free days significantly increased, after VNS. In some instances, subjects had the same total number or sometimes a very small decrease in total number of seizures in a calendar year but they had significantly more consecutive seizure-free blocks. After VNS, the mean number of blocks of seizure-free days increased tenfold ( $\bar{x} 0.85$ to $\bar{x} 8.00$ ), $F(4,24)=2.80, p=.04$ from 1991-1995 while mean seizure frequency in blocks in which there was seizure activity, decreased only from ( $\mathrm{x} 20.14$ to $\bar{x} 17.59$ ) over the same time period (Tables 1, 2). Correlation coefficients between pre-pacemaker implant and all seizure activity to date was $r=.20$ indicating a significant decrease in seizures over time. Comparison of total number of seizures after 24 months of VNS and then after 50 months of stimulation was $r=.85$, demonstrating a consistency in the effect of VNS.

\section{Discussion}

The results from this long term follow up study indicate that decisions to continue or discontinue vagal nerve stimulation in subjects with intractable complex partial seizures can be based on posing the following questions. Is there evidence to show that VNS contributes to the decline and subsequent cessation of seizures?

Statistical analysis comparing total number of seizures prestimulation with total number of seizures post stimulation shows that chronic VNS is having a statistically significant effect in 


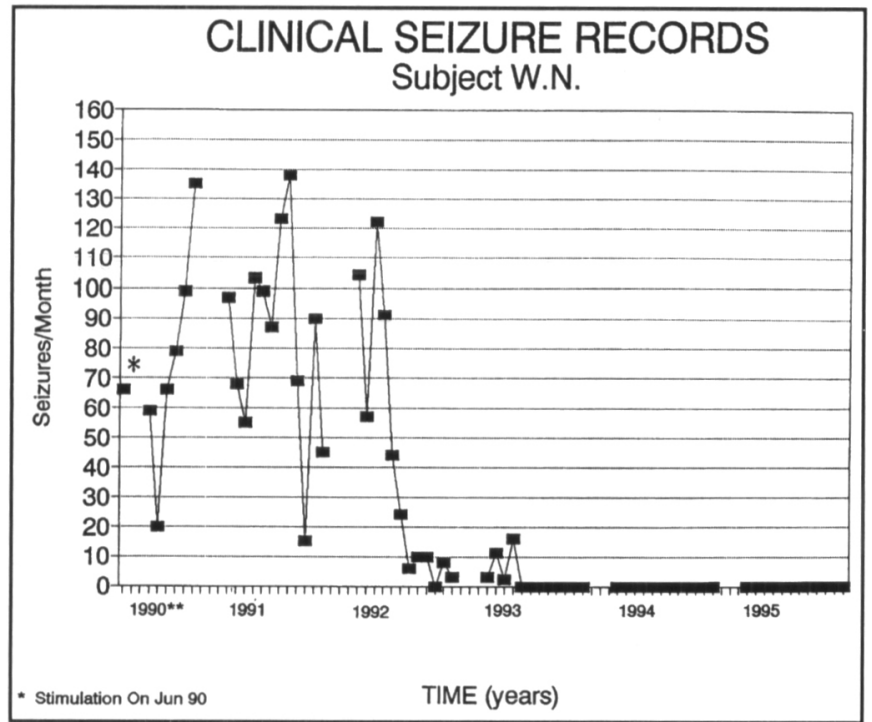

Figure 1: Seizure frequency patterns to cessation and seizure-free episodes.

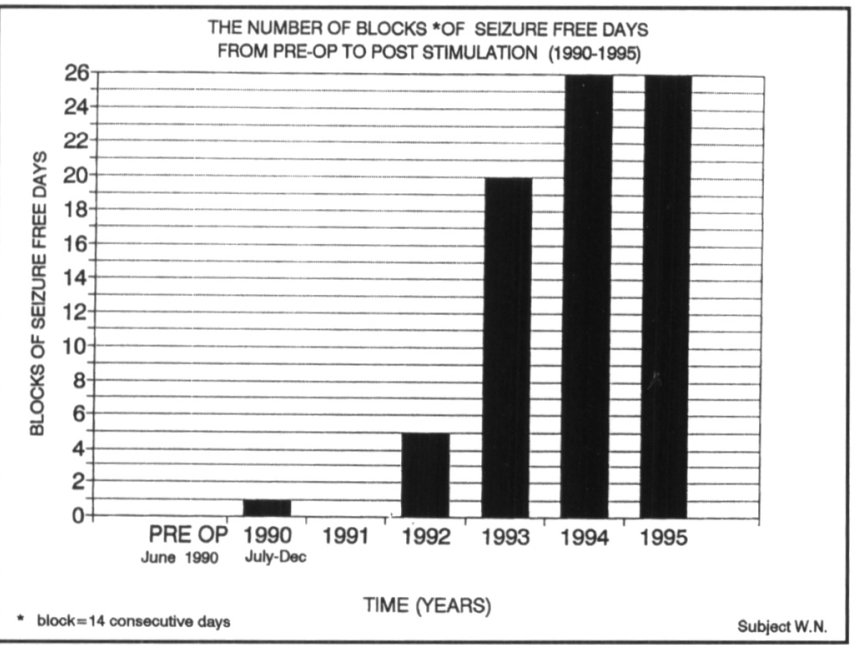

Figure 2: The number of blocks of consecutive seizure-free days from pre-op to post stimulation (1990-1995). 1 year consists of 26 blocks.

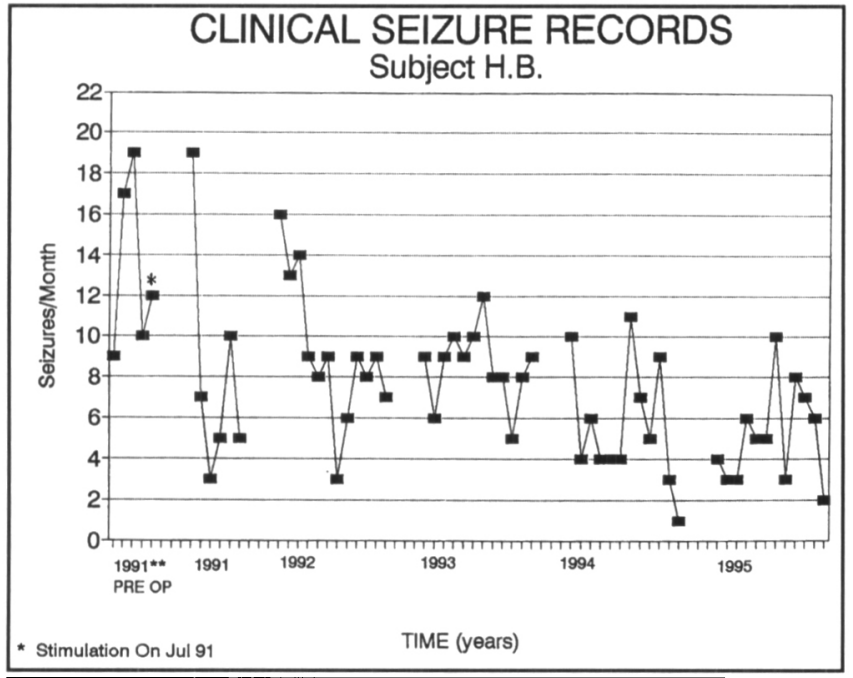

Figure 3: Seizure frequency patterns. ** Subject entered the project in February 1991 and therefore, has 11 months of data.

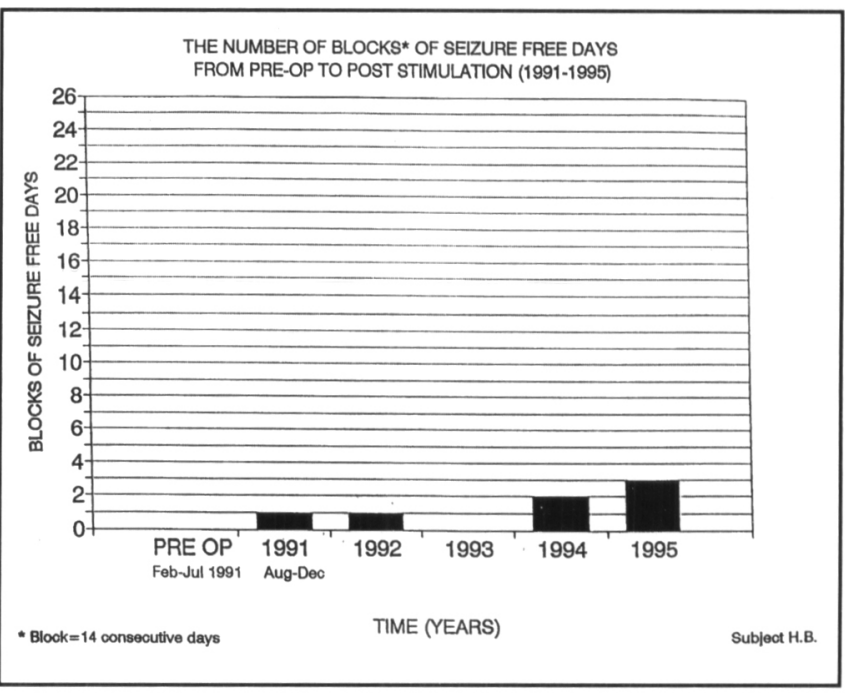

Figure 4: The number of blocks of consecutive seizure-free days from pre-op to post stimulation (1991-1995).

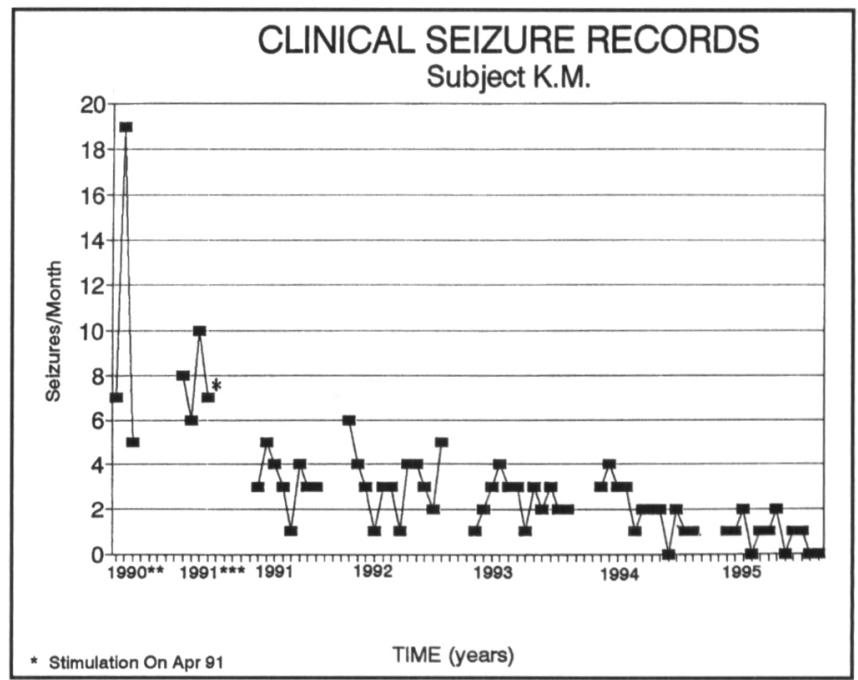

Figure 5: Seizure frequency patterns to cessation. **Pre-op data is from October 1990 to April 1991

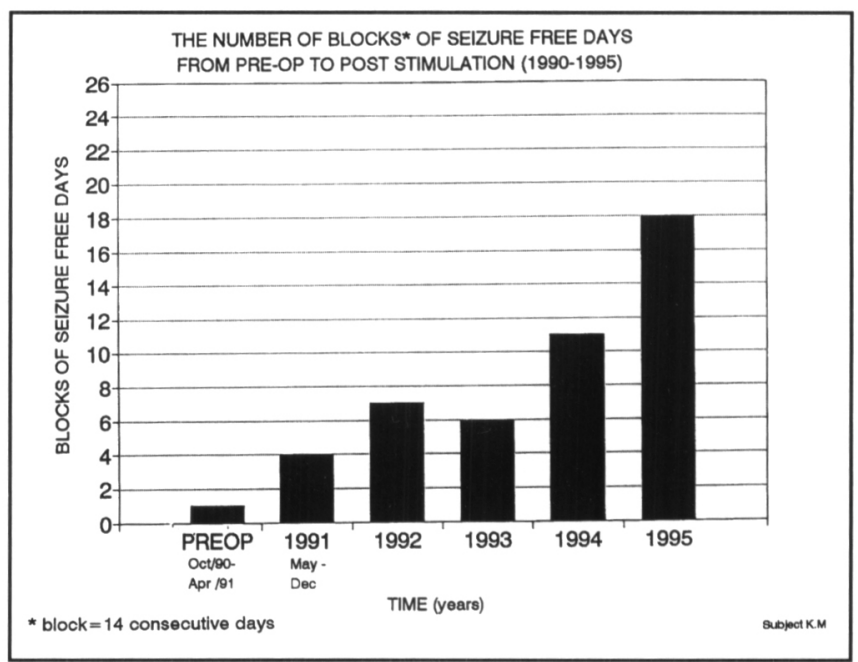

Figure 6: The number of blocks of consecutive seizure-free days from pre-op to post stimulation (1990-1995). 
Table 1: Increase in the Mean Number of Blocks of 14 Consecutive Seizure-free Days from 1991-1995*.

\begin{tabular}{lcc}
\hline Time & Mean Number of Blocks & Significance \\
\hline 1991 & .85 & $\mathrm{~F}(4,24)=2.80$ \\
& & $\mathrm{p}=.04$ \\
1992 & 2.00 & \\
1993 & 4.28 & \\
1994 & 6.57 & \\
1995 & 8.00 & \\
\hline
\end{tabular}

* There was no main effect for the covariate (the actual number of seizure-free blocks before implant). However, the number of seizurefree blocks continues to increase over time (even after being adjusted for pre-implant values).

Table 2: Decrease in the Mean Number of Seizures Within Seizure Filled Blocks.

\begin{tabular}{lcc}
\hline Time & Mean Number of Seizures & Significance \\
\hline 1991 & 20.14 & NS \\
1992 & 23.57 & \\
1993 & 21.14 & \\
1994 & 19.42 & \\
1995 & 17.57 & \\
\hline
\end{tabular}

decreasing seizures and that this effect is constant over time. What criteria are used to determine continuation of VNS in subjects who show inconsistent decreases and increases in total number of seizures?

Our results show that collation of blocks of 14 days of consecutive seizure-free days is a significant outcome measure of the effect of VNS. Significant increases $(p=.04)$ in number of seizure-free blocks after VNS were noted as early as the first year post VNS ( 0 seizure-free blocks pre-implant to a mean of 0.85 seizure-free blocks after the first year post VNS). This effect is consistent, with improvement increasing every year, thereafter. In addition, in the blocks in which subjects did have seizures, there was a decrease in the mean number of seizures over time. These latter data have limited use as indicators of progress from a clinical perspective, because it is difficult to make appropriate decisions concerning the efficacy of VNS based solely on mean values, i.e., a change from a mean of 20.14 seizures per year to 17.54 seizures per year after VNS. However, when the number of consecutive seizure-free days is also used as a clinical outcome measure, the effectiveness of VNS is more accurately assessed, particularly from the perspective of activities of daily living. Even if the total number of seizures in a calendar year remains the same but the number of consecutive seizure-free days increases, the patients have the opportunity to achieve a higher level of independence. If, in some cases, the decrease in seizure frequency is minimal and there are very few consecutive seizure-free days, then decisions concerning the efficacy of VNS may be more accurately determined. The patients in this study have become focused on wellness even though seizure control is not complete. Of the 9 subjects, five have begun formal exercise fitness programs. One subject has obtained employment and one subject who has been seizure-free for $36 \frac{1}{2}$ months drives a car and does volunteer work in the community. One subject who was in a residential home, is now living alone in an apartment and is monitored by a social service agency. One subject who has not shown an improvement in either seizure frequency and/or number of consecutive seizure-free days has also shown no lifestyle changes. Limitations of this study are that there was no consistent measure of number of seizures before VNS between subjects prior to stimulation. Future studies should include documenting the number of seizures for at least a year prior to surgery. This limitation does not alter the fact that number of consecutive seizurefree days is also a significant efficacy outcome measure with considerable clinical importance in the management of patients with epilepsy.

\section{ACKNOWLEDGEMENTS}

We thank Mary Lou Schmuck, B.A., for assistance with statistical analyses, and Programme for Educational Development, Education Services, McMaster University Medical Centre.

\section{REFERENCES}

1. Bailey P, Bremer F. A sensory cortical representation of the vagus nerve with a note on the effects of low blood pressure on the cortical electrogram. J Neurophysiol 1938; 1: 405-412.

2. Zanchetti A, Wang SC, Moruzzi G. The effect of vagal stimulation on the EEG pattern of the cat. Electroencyphalogr Clin Neurophysiol 1952; 4: 357-361.

3. Chase MH, Nakamura Y. Cortical and Sub cortical EEG patterns of response to afferent abdominal vagal stimulation: neurographic correlates. Physiol Behav 1968; 3: 605-610.

4. Puizillot JJ, Foutz AS. Vago-aortic nerves stimulation and REM sleep: evidence for REM-triggering and REM maintenance factor. Brain Res 1976; 111: 181-184.

5. Puizillot JJ. Nayau du faisccau solitaire, serotonine et regulation de la vigilance. Rev Electroencephalogr Neuro-physiol Clin 1986; 1695: 106.

6. Penaloza Rojas JH. Electroencephalographic synchronization resulting from direct current application to the vagus nerve. Exp Neurol 1964; 9: 367-371.

7. Stoica I, Tudor I. Vagal trunk stimulation influences on epileptic spiking focus activity. Rev Roum Neurol 1967; 4: 287-295.

8. Stoica I, Tudor I. Effects of vagus afferents on strych-ninic focus of coronal gyrus. Rev Roum Neurol 1968; 5: 203-210.

9. Woodbury DM, Woodbury JW. Effects of vagal stimulation and Experimentally-induced seizures in rats. Epilepsia 1990; 31 (Suppl. 2): S7-S20.

10. Zabara J. Time course of seizure control to brief, repetitive stimuli. Epilepsia 1985; 26: 518.

11. Lockard JS, Congdon WC, Ducharme LL. Feasibility and safety of Vagal Stimulation: the monkey model. Epilepsia 1990; 31 (Suppl. 2): S20-6.

12. Penry JK, Dean JC. Prevention of intractable partial seizures by intermittent vagal stimulation in humans: preliminary results. Epilepsia 1990; 31 (Suppl. 2): S40-S44.

13. Uthman BM, Wilder BJ, Penry JK, et al. Treatment of epilepsy by stimulation of the vagus nerve. Neurology 1993; (43) 13381345.

14. George R, Salinsky M, Kuzniecky R, et al. and the First International Vagus Nerve Stimulation Study Group. Epilepsia 1994; 35(3): 637-643.

15. Naritoku DK. Vagus Nerve stimulation: continuation rates as a measure of therapeutic outcome - results from four studies. AES Proceedings. Epilepsia 1995; 36(4): 157. 